\title{
ENCAPSULAÇÃO DE LIPASE DE Burkholderia cepacia EM SILICA AEROGEL NA PRESENÇA DE LÍQUIDO IÔNICO PARA SÍNTESE DE ÉSTERES ETIILICOS
}

\author{
A. S. BARBOSA ${ }^{1}$, J. A. LISBOA ${ }^{1}$, N. B. CARVALHO ${ }^{1}$, L. S. FREITAS ${ }^{2}$,A. T. FRICKS ${ }^{1}$, S. $^{2}$ \\ MATTEDI $^{3}$, A. S. LIMA ${ }^{1}$, E. FRANCESCHI e C. M. F. SOARES ${ }^{1}$ \\ ${ }^{1}$ Universidade Tiradentes, Instituto de Tecnologia e Pesquisa \\ ${ }^{2}$ Universidade Federal de Sergipe, Departamento de Química \\ ${ }^{3}$ Universidade Federal da Bahia, Departamento de Engenharia Química \\ E-mail para contato: andinhobarbosa@hotmail.com
}

\begin{abstract}
RESUMO-O objetivo deste trabalho foi avaliar o efeito do uso de líquido iônico prótico - LIP (pentanoato de N-metilmonoetalonamina - $\mathrm{C}_{5}$ ) na lipase de Burkholderia cepacia(LBC) imobilizada por encapsulação em sílica aerogel modificado. Nas reações de transesterificação foram utilizados etanol:óleo de girassol $(7: 1)$ e $20 \% \mathrm{~m} / \mathrm{m}$ de biocatalisadoresimobilizados (BIs) $\left(40^{\circ} \mathrm{C}, 80 \mathrm{rpm}, 8\right.$ 96h).Os ésteres etílicos foram analisados por cromatografia em fase gasosa(FID).Os BIs na ausência de LIP não apresentaram conversão de ésteres etílicos.Após a adição do LIP na preparação do BIobteve-se a conversão máxima de ésteres etílicos de $48 \%$ em $48 \mathrm{~h}$. Os suportes e BIs foram caracterizados morfologicamente pelo método de Brunauer-Emmett-Teller (BET), análise físicoquímica portermogravimetria (TG) e composição química (FTIR).As caracterizações evidenciaram a eficiência do líquido iônico prótico na formação do aerogel e a presença da lipase nestes sistemas imobilizados.
\end{abstract}

\section{INTRODUÇÃO}

As lipases são enzimas seletivas utilizadas como biocatalisadores em bioprocessos por meio de diversas reações, como: hidrólise, esterificação, trasesterificação, entre outras.A utilização de matrizes sol-gel para a encapsulação de enzimas permite a estabilização da estrutura terciária da proteína, devido à reticulação do gel (SOUZA et al., 2012).Além disso, alguns estudos demonstraram que a atividade enzimática de lipases imobilizados pela técnica sol-gel apresentam melhores resultados quando a secagem é realizada em meio supercrítico (aerogel) quando comparados à secagem tradicional (xerogel) (PIERRE e BUISSON, 2001; REETZ et al., 1996).

O aerogel por possuir a base em sílica, sendo extremamente poroso com uma área de superfície específica muito alta e volumes e diâmetros de poros maiores quando comparados a outros suportes, se tornou um suporte muito interessante e viável para a imobilização de biomoléculas (NOVAK et al., 2003). Uma nova e promissora possibilidade é a utilização de aditivos, como os líquidos iônicos (LI) nos diferentes métodos de imobilização de enzimas utilizando a técnica sol-gel (LEE et al., 2007; SOUZA et al., 2012). 
A aplicação de aditivos durante o processo de síntese de suportes e biocatalisadores imobilizados é uma área de pesquisa ainda recente, pois, uma das principais funções dos mesmos é a formação de uma matriz ordenada na síntese de sol-gel, que além de poder proteger as enzimas da inativação por diversos efeitos durante o processo de imobilização, pode ainda aumentar a sua estabilidade operacional (SOARES et al., 2005).

Dentre os aditivos destacam-se os líquidos iônicos (LI) que devido a excelentes propriedades como: baixa pressão de vapor e boa estabilidade dentro de um amplo intervalo de temperatura, o que impede a emissões de gases poluentes, são considerados uma boa alternativa como solventes, com potencial de aplicações a nível industrial, dentre elas, as que envolvem a biocatálise (ALVAREZ et. al. 2011; ASLANOV, 2011).

Desta forma, o objetivo deste trabalho foi avaliar o efeito do uso do LIP na LBC imobilizada por encapsulação em sílica aerogel modificada com LIP para a síntese de ésteres etílicos, além das características morfológicas e físico-químicas do biocatalisador imobilizado na sílica aerogel.

\section{METODOLOGIA}

\subsection{Imobilização da lipase}

A enzima utilizada foi a lipase de Burkholderia cepacia $(\mathrm{BC})(\geq 30,000 \mathrm{U} / \mathrm{g}, \mathrm{pH} 7,0$, $50^{\circ} \mathrm{C}$, adquirida comercialmente da Sigma-Aldrich). A matriz pura aerogel (MP) e os biocatalisadores imobilizados por encapsulação $(\mathrm{EN})$ foram obtidos pela técnica sol gel conforme descrito por Souza et al. (2013) para xerogelna ausência ou presença de $1 \%(\mathrm{~m} / \mathrm{v})$ de líquido iônico prótico (pentanoato de $\mathrm{N}$-metilmonoetanolamina $-\mathrm{C}_{5}$ ). A obtenção do aerogel foi realizada utilizando meio pressurizado com $\mathrm{CO}_{2}$ nas seguintes condições de secagem: 100 bar, $25^{\circ} \mathrm{C}$ e vazão de $2 \mathrm{~mL} / \mathrm{min}$.

\subsection{Síntese de ésteres etílicos}

As reações foram realizadas em reatores fechados com capacidade de $25 \mathrm{~mL}$ contendo $12 \mathrm{~g}$ de substrato (óleo de girassol e etanol), na proporção de $7: 1$, sob agitação constante de $80 \mathrm{rpm}$ e temperatura de $40^{\circ} \mathrm{C}$ por até $96 \mathrm{~h}$. Foi utilizado $20 \%(\mathrm{~m} / \mathrm{m})$ de biocatalisador em relação à massa total de reagentes. Os ésteres de etila formados foram analisados por cromatografia em fase gasosa (FID) usando o modelo Varian CG 3800 (Varian, Inc., EUA). A conversão da transesterificação foi calculado levando em consideração a massa dos ésteres detectados por análise cromatográfica e a massa total teórica de ésteres baseado na razão molar da reação.

\subsection{Caracterização Morfológica (BET) e Físico-Química (TG e FTIR)}

A análise morfológica da superfície das partículas das matrizes aerogéis e dos biocatalisadores imobilizados foi realizadas pelo método Brunauer-Emmett-Teller (BET) que determinou a área superficial específica $\left(\mathrm{m}^{2} / \mathrm{g}\right)$, diâmetro do poro $(\mathrm{nm})$ e volume do poro $\left(\mathrm{cm}^{3} / \mathrm{g}\right)$. As perdas de massa foram determinadas por termogravimetria (TG, DTG-60H 
Shimadzu). E a estrutura química dos sistemas foi investigada por infravermelho (espectrômetro FTIR BOMEM MB-100).

\section{RESULTADOS E DISCUSSÕES}

\subsection{Síntese de ésteres etílicos}

$\mathrm{Na}$ reação de transesterificação do óleo de girassol foram testados para a lipase encapsulada em sílica aerogel na presença (ENLI) e ausência (EN) de LIP a $40^{\circ} \mathrm{C}, 80 \mathrm{rpm}$, em até 96 horas (Figura 1). Os resultados mostraram que para os biocatalisadores imobilizados em aerogel na ausência de LIP (EN) não apresentaram conversão de ésteres etílicos,já o sistema imobilizado na presença de LIP verificou-sea conversão de $48 \%$ de ésteres etílicos em $48 \mathrm{~h}$ de reação.Esse comportamento pode ser explicado pela característica do LIP utilizado neste estudo, que por possuir um caráter hidrofóbico, possibilita a formação de uma camada de hidratação em torno da enzima favorecendo a atividade lipolítica e induzindo a água para mais próximo da enzima (SOUZA et al., 2013).A técnica de encapsulação em aerogel foi utilizada por NASSARENDDINE et al. (2008) para imobilização da lipase comercial de Candida antartica e Lipozyme ${ }^{\circledR}$ na síntese utilizando óleo de semente de girassol no qual se observou $90 \%$ de conversão de ésteres etílicos após 50 h aproximadamente.

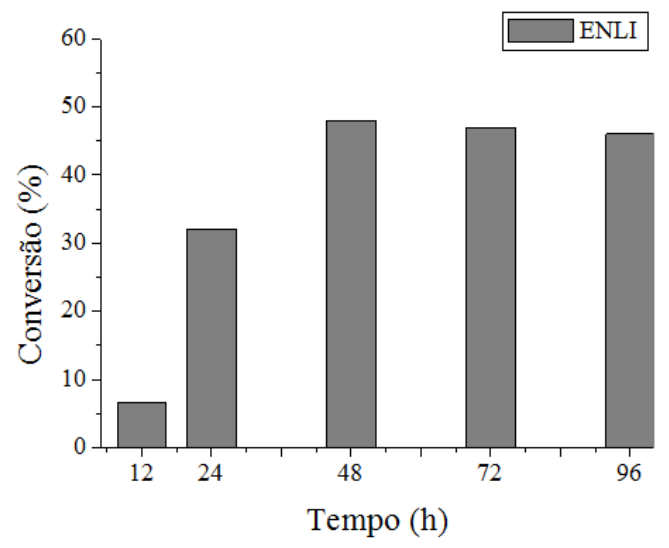

Figura 1. Conversão de ésteres etílicos em função do tempona reação de transesterificação do óleo de girassol e etanol $(7: 1)$ à $40^{\circ} \mathrm{C}$ e $80 \mathrm{rpm}$ utilizando LBC encapsulada em sílica aerogel na presença de LIP.

Em estudos realizados anteriormente com a utilização daLBC imobilizada em sílica xerogel modificada com LI, os resultados obtidos neste trabalho evidenciaram o efeito estabilizante do LI testado $\left(\mathrm{C}_{5}\right)$ e confirmam dados da literatura, nos quais indicam um considerável aumento da atividade catalítica por meio da imobilização da lipase na presença de LIP(SOUZA et al., 2013). A partir dos resultados obtidos, pode-se sugerir que a atuação do aditivo no processo de imobilização promove um aumento na eficiência catalítica da enzima e a minimização dos efeitos difusionais, possivelmente por promover a estabilização da mesma durante a liberação de álcool no processo de reticulação do alcóxido de silício na etapa de imobilização da enzima, além de proteger a matriz aerogel do encolhimento, do colapso dos poros da rede do gel e do caráter hidrofóbico do LI influenciando na interação entre a enzima e o suporte (SOUZA et al., 2013). 


\subsection{Caracterização morfológica (B.E.T)}

$\mathrm{Na}$ Tabela 1 observa-se a área superficial específica, volume e tamanho médio de poros para a matriz aerogel e lipase imobilizada em sílica aerogel na ausência e presença de LIP estão resumidos na Tabela 1.Para a matrize puraaerogel a presença de líquido iônico (ENLI)verificou-se efeitos positivos sobre o diâmetro e volume dos poros.Entretanto, o biocatalisador imobilizado com LIP apresentou a diminuição dovolume e diâmetro de poros reduzidos $\left(0,4 \mathrm{~cm}^{3} \mathrm{~g}^{-1}\right.$ e $\left.5,9 \mathrm{~nm}\right)$ em comparação com o biocatalisadore $E N\left(0,5 \mathrm{~cm}^{3} \mathrm{~g}^{-1}\right.$ e 8,2nm) na ausência de LIP. Este efeito pode ser devido ao preenchimento maior dos poros pela lipase, devido a afinidade hidrofóbica do ácido pentanóico $\mathrm{N}$-metilmonoetanolamina $\left(\mathrm{C}_{5}\right)$ durante a contração, solidificação, na etapa de envelhecimento, a secagem em meio pressurizado do gel na interação entre a enzima e o suporte.

Tabela 1. Influência do líquido iônico prótico utilizado como aditivo em aerogel nas propriedades estruturais por adsorção-dessorção de nitrogênio para matriz pura e biocatalisadores imobilizados por diferentes métodos.

\begin{tabular}{|c|c|c|c|}
\hline Ensaio & $\begin{array}{c}\text { Área superficial } \\
\text { específica } \\
\left(\mathbf{m}^{\mathbf{2}} \mathbf{g}^{-\mathbf{1}}\right)\end{array}$ & $\begin{array}{c}\text { Volume dos poros } \\
\left(\mathbf{c m}^{\mathbf{3}} \mathbf{g}^{-\mathbf{1}}\right)\end{array}$ & $\begin{array}{c}\text { Diâmetro dos poros } \\
(\mathbf{n m})\end{array}$ \\
\hline MP & 81 & 0,04 & 1,1 \\
\hline MPLI & 322 & 0,8 & 5,0 \\
\hline EN & 131 & 0,5 & 8,2 \\
\hline ENLI & 147 & 0,4 & 5,9 \\
\hline
\end{tabular}

A utilização de sílica xerogel modificada com líquido iônico aprótico pode permitir a penetração da lipase no interior dos poros (por causa do aumento dos mesmos), e dessa forma elevar a carga de enzimas encapsuladas e, consequentemente, favorecendo o aumento da atividade de acordo com estudos realizados por Fernandez-Lafuente (2009). Um perfil semelhante foi observado também para xerogel por Vila-Real et al. (2011), onde a adição de líquidos iônicos aprótico da família dos imidazólios no processo de imobilização pela técnica sol-gel teve um papel importante no desempenho da enzima, por afetar as características estruturais do biocatalisador imobilizado.

Estudos realizados por Souza et al. (2013) relataram resultados inferiores em relação ao diâmetro e volume de poros na adição do líquido iônico $\mathrm{C}_{5}$ durante o processo de imobilização da lipase de $\mathrm{BC}$ em matriz xerogel quando comparados ao aerogel. Nestes resultados foram observados o alargamento dos poros de 3 para 5,9 nm e o volume de poros de $0,08 \mathrm{~cm}^{3} \mathrm{~g}^{-1}$ para $0,4 \mathrm{~cm}^{3} \mathrm{~g}^{-1}$, minimizando assim os efeitos difusionais características desta técnica de imobilização confirmados pelo aumento da eficiência catalítica na síntese de ésteres etílicos (Figura 1). Este comportamento também foi relatado por Zarcula et al. (2010) durante a encapsulação de lipase numa matriz hidrofóbica, uma vez que os líquidos iônicos hidrofóbicos induzem alterações significativas na estrutura porosa do suporte do biocatalisador. 


\subsection{Caracterização físico-química}

\subsubsection{Termogravimetria}

A análise termogravimétrica fornece uma ferramenta importante para estudos da estrutura e da composição orgânica e da perda de água em função da degradação térmica da matriz pura, da lipase de Burkholderia cepacia livre e dos biocatalisadores imobilizados.Os termogramas foram divididos em três regiões para simplificar as discussões sobre a análise termogravimétrica (Tabela 2).

Região I, onde a temperatura chega até aproximadamente $200{ }^{\circ} \mathrm{C}$, ocorre a perda de peso associada principalmente com a decomposição de grupos amino e a desidratação, geralmente grupos orgânicos. A Região II, que compreende entre 200 e $600^{\circ} \mathrm{C}$, está associada com a condensação de grupos silanol e alguma perda de componentes orgânicos $(\mathrm{C}, \mathrm{H}, \mathrm{O}$ e $\mathrm{N})$ sob a forma de compostos voláteis presentes ou formados até o início da decomposição biológica, incluindo a lipase e a presença de grupos silanois do TEOS não-reagido, que estão presentes na sílica, devido à incompleta reação sol-gel (MUKHERJEE et al, 2009). E região III, onde a perda de massa é associada com as reações desidroxilação finais e de carbonização final de compostos orgânicos, acarretando na degradação completa do material ou sua estabilidade térmica (SOARES et al., 2004).

Tabela 2: Perda total e parcial de massa observada na lipase de Burkholderia cepacia imobilizada em matriz aerogel na presença de líquido iônico prótico.

\begin{tabular}{|l|c|c|c|c|}
\hline \multicolumn{1}{|c|}{ Ensaio } & $\begin{array}{c}\text { Região I } \\
\left(\mathbf{0}^{-200} \mathbf{C}\right)\end{array}$ & $\begin{array}{c}\text { Região II } \\
\left(\mathbf{2 0 0}-\mathbf{6 0 0}^{\circ} \mathbf{C}\right)\end{array}$ & $\begin{array}{c}\text { Região III } \\
\left(\mathbf{6 0 0}^{-1000} \mathbf{~ C )}\right)\end{array}$ & $\begin{array}{c}\text { Perda total } \\
\text { de massa (\%) }\end{array}$ \\
\hline BC Livre & 8,32 & 82,32 & 9,16 & 99,81 \\
\hline MP & 10,37 & 6,02 & 0,58 & 16,90 \\
\hline MPLI & 41,98 & 3,67 & 0,65 & 46,31 \\
\hline EN & 33,62 & 15,72 & 1,66 & 51,03 \\
\hline ENLI & 16,74 & 19,40 & 1,91 & 37,99 \\
\hline
\end{tabular}

Na Tabela 2 pode-se observar que o valor obtido na perda de massa total foi de $16,90 \%$ para MP com a secagem em meio pressurizado, onde se verificou a maior perda de massa na região I, cerca de $10,37 \%$, possivelmente devido a presença de água na superfície do suporte. Concomitantemente para MPLI, a maior perda parcial de massa ocorreu na região I (41,98\%). O valor de perda de massa foi cerca de 4 vezes maior na região I quando comparado o MPLI com MP. Este comportamento pode estar associado ao uso do líquido iônico prótico, ao aumento da quantidade e diâmetro dos poros da matriz pura e por modificar a hidrofobicidade do microambiente dos poros que exercem influência no nível de umidade da mesma. Segundo Meera et al. (2011) perfil similar confirma os valores da região I apresentados na Tabela 2, que demonstram que matrizes preparadas com líquido iônico aprótico apresentam uma perda de massa maior na região I, quando comparados a matrizes sem o aditivo. 
Para as amostras dos biocatalisadores imobilizados, observou-se uma tendência no aumento de perda de massa na região II (15,72\% e 19,40\% para EN e ENLI respectivamente) quando comparado com MP e MPLI (6,04\% e 3,67\%, respectivamente), possivelmente influenciados pela presença de água e alguma perda de componentes orgânicos nos interstícios do aerogel.Em temperaturas mais elevadas (Região III), a perda de massa foi insignificante, além disso, no caso de enzimas imobilizadas, essa região não é de interesse, devido à carbonização completa de compostos orgânicos, dentre eles a lipase (BARÃO et al., 2013).

\subsubsection{Espectroscopia de Infravermelho com Transformada de Fourrier}

Os espectros de FTIR das sílicas aerogéis e do biocatalisador imobilizado em sílica aerogel preparados na ausência e presença de LIPs são apresentados na Figuras 2. O espectro de suporte aerogel deste estudo e o xerogel obtido pela mesma técnica por Souza et al. (2013) foram observadas bandas similares determinadas nos comprimentos de onda entre 1000-1100 que corresponde à ligação Si-O-R, $650 \mathrm{~cm}^{-1}(\mathrm{Si}-\mathrm{O}-\mathrm{Si}), 800 \mathrm{~cm}^{-1}(\mathrm{Si}-\mathrm{O}-\mathrm{Si}), 450 \mathrm{~cm}^{-1}(\mathrm{Si}-\mathrm{O}) \mathrm{e}$ dos grupos - $\mathrm{OH}$ na faixa entre 3400 e $3500 \mathrm{~cm}^{-1}$. Para os espectros obtidos para os biocatalisadores imobilizados mostram que além das bandas características dos grupos silanóis, a presença de bandas nas faixas de comprimento de onda entre 1600 e $1700 \mathrm{~cm}^{-1}$ (amida I), $1390 \mathrm{~cm}^{-1}$ correspondente a grupos $\mathrm{C}-\mathrm{H}$ com ligações de $\mathrm{CH}_{3}$ e $695 \mathrm{~cm}^{-1}$ (amida IV e/ou V) evidenciando a eficiência da imobilização das lipases de BC na matriz aerogel.

De acordo com a literatura, as bandas características do estiramento da ligação N-H de amida I são referentes às vibrações de estiramento da ligação $\mathrm{C}=\mathrm{O}$ acoplada ao estiramento da ligação C-N. Estes modos vibracionais são sensíveis para ligação de hidrogênio e acoplamento entre transição dipolar das ligações peptídicas adjacentes e, portanto, são sensíveis à estrutura secundária da enzima. As amidas IV e V são, respectivamente, devido à ligação OCN e ao redor do plano de ligação -NH (PORTACCIO et al., 2011; MOHIDEM \& MAT, 2011).

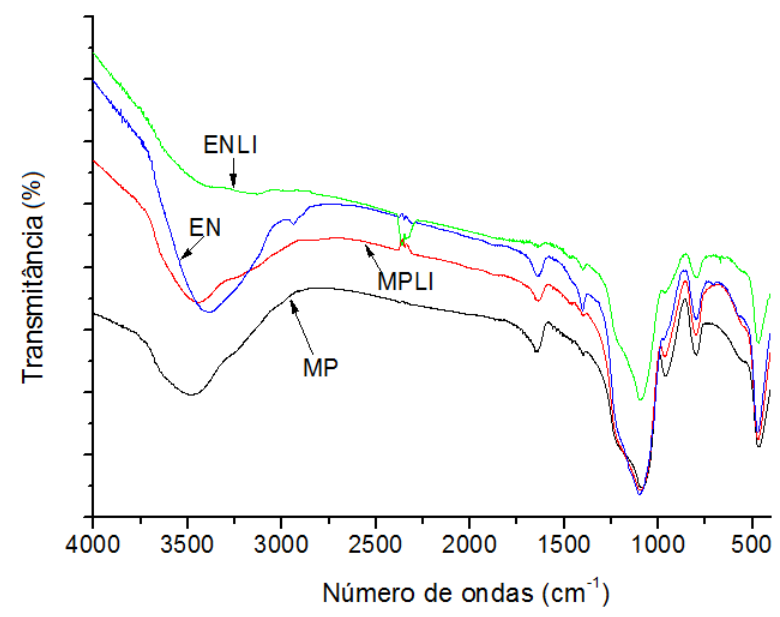

Figura 2. Espectro de FTIR para sílica aerogel (MP e MPLI) e biocatalisadores imobilizados em matriz aerogel na ausência (EN) e presença (ENLI) de líquido iônico prótico.

\section{CONCLUSÃO}


A análise da eficiência catalítica e avaliação das propriedades físico-químicas e morfológica mostraram o efeito positivo do líquido iônico na imobilização, na qual se verificou a conversão em ésteres etílicos somente após a adição do LIP na preparação do BI. Esse comportamento pode ser justificado pela minimização dos efeitos difusionais devido o aumento do volume e tamanho de poros e a interação entre a lipase e a sílica aerogel pelo caráter hidrofóbico do LIP.

\section{REFERÊNCIAS}

ALVAREZ, V. H.; MATTEDI, S.; MARTIN-PASTOR, M., AZNAR, M.; IGLESIAS, M. Thermophysical properties of binary mixtures of \{ionic liquid 2-hydroxy ethylammonium acetate + (water, methanol, or ethanol) \}. Journal Chemistry Thermodynamics, v. 43, p. 9971010, 2011.

ASLANOV, L. A. Ionic liquids: Liquid structure. Journal of Molecular Liquids, v. 162, p. 101-104, 2011.

BARÃO, C.E.; DE PARIS, L. D.; DANTAS, J. H.; PEREIRA, M. M.; FILHO, L. C.; CASTRO, H. F.; ZANIN, G. M.; MORAES, F. F.; SOARES, C. M. F. Characterization of biocatalysts prepared with Thermomyces lanuginosus lipase and different silica precursors, dried using aerogel and xerogel techniques. Applied Biochemistry Biotechnology, DOI: 10.1007/s12010-013-0533-3, 2013.

FERNANDEZ-LAFUENTE R. Stabilization of multimeric enzymes:strategies to prevent subunit dissociation. Enzyme and Microbial Technology, v. 45, p. 405-18, 2009.

LEE, S. H.; DOAN, T. T. N.; HA, S. H. H.; CHANG, W. J. Influence of ionic liquids as additives on sol-gel immobilized lipase. Journal of Molecular Catalysis B: Enzymatic,v. 47, p. 129-134, 2007.

MOHIDEM N. A.; MAT H. B. Catalytic activity and stability of laccase entrapped in sol-gel silica with additives. The Journal of Sol-Gel Science and Technology, DOI 10.1007/s10971011-2596-3, 2011.

MUKHERJEE I.; MYLONAKIS A.; GUO Y.; SAMUEL S.P.; LI S.; WEI R.Y.; KOJTARI A.; WEI Y. Effect of nonsurfactant template content on the particle size and surface area of monodisperse mesoporous silica nanospheres. Microporous and Mesoporous Materials, v. 122, p. 168-174, 2009.

NASSREDDINE, S; KAROUT, M.; CHRIST, M. L.; PIERRE, A.C. Transesterification of a vegetal oil with methanol catalyzed by a silica fibre reinforced aerogel encapsulated lipase. Journal Applied Catalysis A: General, v. 344, p. 70-77, 2008.

NOVAK, Z.; HABULIN, M.; KRMELJ, V.; KNEZ, Z. Silica aerogels as supports for lipase catalyzed esterifications at sub-and supercritical conditions. Journal of Supercritical Fluids, v. 27, p. 169-178, 2003.

PIERRE, A.; BUISSON, P. Influence of the porous texture of silica gels on the enzymatic activity of lipases in esterification reactions. Journal of Molecular Catalysis B: Enzymatic, v. 11, p. 639-647, 2001. 
PORTACCIO, M.; DELLA-VENTURA, B.; MITA, D. G.; MANOLOVA, N.; STOILOVA, O.; RASHKOV, I.; LEPORE, M. FT-IR microscopy characterization of sol-gel layers prior and after glucose oxidase immobilization for biosensing applications. The Journal of Sol-Gel Science and Technology, v. 57, p. 204-211, 2011.

REETZ, M.T.; ZONTA, A.; SIMPELKAMP J. Efficient immobilization of lipases by entrapment in hydrophobic sol-gel materials. Biotechnology and Bioengineering, v. 49, p. 527-534, 1996.

SOARES, C. M. F. ; CASTRO, H. F.; ITAKO, J. E.; MORAES, F. F.; ZANIN, G. M. Characterization of sol-gel bioencapsulates for hydrolysis and synthesis. Applied Biochemistry and Biotechnology, v. 121, p. 845-859, 2005.

SOARES, C. M. F.; SANTOS O.A., OLIVO J.E., CASTRO, H. F.; MORAES, F.F., ZANIN, G.M. Influence of the alkyl-substituted silane precursor on sol-gel encapsulated lipase activity.Journal of Molecular Catalysis B - Enzymatic, v. 29, p. 69-79, 2004.

SOUZA, R. L.; FARIA, E. L. P.; FIGUEIREDO, R. T.; FREITAS, L. S.; IGLESIAS, M.; MATTEDI, S.; ZANIN, G. M.; SANTOS, O. A. A.; COUTINHO, J. A. P.; LIMA, A. S.; SOARES, C. M. F. Protic ionic liquid as additive on lipase immobilization using silica solgel. Enzyme and Microbial Technology, v. 52, p. 141-150, 2013.

SOUZA, R. L.; RESENDE, W.C.S.; BARÃO, C.E.; ZANIN, G. M.; CASTRO, H. F.; SANTOS, O.A.A. ; FRICKS, A.T. ; ITP/UNIT, R. T. F. -. P.; LIMA, A.S. ; SOARES, C. M. F. Influence of the use of Aliquat 336 in the immobilization procedure in sol-gel of lipase from Bacillus sp. ITP - 001. Journal of Molecular Catalysis. B, Enzymatic, v. 84, p. 152-159, 2012.

VILA-REAL H.; ALFAIA A. J.; ROSA J. N.; GOIS P. M. P.; ROSA M. E.; CALADO A. R. T. $\alpha$ - Rhamnosidase and $\alpha$-glucosidase expressed by naringinase immobilized on new ionic liquid sol-gel matrices: activity and stability studies. Journal of Biotechnology, v. 152, p. $147-58,2011$.

ZARCULA C.; CORÎCI, L.; CROITORU, R.; URSOIU, A.; PETER, F.; Preparation and properties of xerogels obtained by ionic liquid incorporation during the immobilization of lipase by the sol-gel method. Journal of Molecular Catalysis B: Enzymatic, v. 65, p. 79-86. 2010.

ZARCULA, C.; CROITORU, R.; CORÎCI, L.; CSUNDERLIK, C.; PETER, F.. Improvement of Lipase Catalytic Properties by Immobilization in Hybrid Matrices. World Academy of Science, Engineering and Technology, v. 52: p. 179 - 184, 2009. 